\title{
Performance analysis of a novel system combining a dual loop organic Rankine cycle (ORC) with a gasoline engine
}

\author{
E.H. Wang ${ }^{\text {a }}$, H.G. Zhang ${ }^{\mathrm{a}, *}$, Y. Zhao ${ }^{\mathrm{b}}$, B.Y. Fan ${ }^{\mathrm{a}}$, Y.T. Wu ${ }^{\mathrm{a}}$, Q.H. Mu ${ }^{\mathrm{c}}$ \\ ${ }^{a}$ College of Environmental and Energy Engineering, Beijing University of Technology, Pingleyuan No. 100, 100124 Beijing, China \\ ${ }^{\mathrm{b}}$ Institute of Mechanics, Chinese Academy of Sciences, Beisihuanxi Road No. 15, 100190 Beijing, China \\ ${ }^{\mathrm{c}}$ Bureau of Planning E' Finance, Chinese Academy of Sciences, Sanlihe Road No. 52, 100864 Beijing, China
}

\section{A R T I C L E I N F O}

Article history:

Received 5 September 2011

Received in revised form

13 February 2012

Accepted 4 April 2012

Available online 12 May 2012

\section{Keywords:}

Organic Rankine cycle

Waste-heat recovery

Gasoline engine

Performance analysis

Performance map

\begin{abstract}
A B S T R A C T
An organic Rankine cycle (ORC) can be used to harness the wasted heat from an internal combustion engine. In this paper, the characteristics of a novel system combining a gasoline engine with a dual loop ORC which recovers the waste heat from both the exhaust and coolant systems is analyzed. A high temperature loop recovers the exhaust heat while a low temperature loop recovers both the residual high temperature loop heat and the coolant heat. The performance map of a gasoline engine is measured on an engine test bench and the heat quantities wasted by the exhaust and coolant systems are calculated and compared within the engine's entire operating region. Based on this data, the working parameters of a dual loop ORC are defined, and the performance of a combined engine-ORC system is evaluated across this entire region. The results show that the net power of the low temperature loop is higher than that of the high temperature loop, and the relative output power improves by from 14 to $16 \%$ in the peak effective thermal efficiency region to $50 \%$ in the small load region, and the absolute effective thermal efficiency increases by $3-6 \%$ throughout the engine's operating region.
\end{abstract}

() 2012 Elsevier Ltd. All rights reserved.

\section{Introduction}

Energy conservation and environmental protection have become ever more important with the rapid development of global industrialization and urbanization. Huge amounts of energy are consumed by the internal combustion engines used on all kinds of vehicles, with much of this energy wasted by the exhaust and cooling systems. From the viewpoint of thermal equilibrium, the useful output power of a gasoline engine accounts for only a small part of the total energy generated by fuel combustion. Exacerbating this problem is that these combustion products from internal combustion engines also cause serious environmental issues. Thus, engine waste-heat recovery could improve fuel thermal efficiency, reserve fuel consumption, and reduce engine emissions. An organic Rankine cycle (ORC) can be adopted to harness the low-grade wasted heat from these systems. Moreover, the thermal efficiency of an ORC is the highest among all the technical solutions used to recover low-grade waste heat, and is the technology closest to being usable in mass production at the present.

When designing an ORC, special attention must be paid to the choice of appropriate working fluid based on the heat source

\footnotetext{
* Corresponding author. Tel.: +8610 6739 2469; fax: +86 1067392774 .

E-mail address: zhanghongguang@bjut.edu.cn (H.G. Zhang).
}

temperature, an important factor that affects the ORC's thermal and exergetic efficiencies. Desai and Bandyopadhyay selected 16 different organic fluids and adopted a new methodology represented by a grand composite curve to integrate and optimize an ORC [1]. Sauret and Rowlands selected five high-density working fluids for ORCs using moderate-temperature geothermal heat sources. After optimizing the design using radial-inflow turbines for each cycle, the net power output was largest for the ORC system using R134a as the working fluid [2]. Hung et al. investigated Rankine cycles which used organic fluids as the working fluid for converting low-grade energy (such as from a solar pond). Results indicated that wet fluids with very steep saturated vapor curves in a $T-S$ diagram had better overall energy conversion efficiencies than that of dry fluids [3]. Saleh et al. conducted a thermodynamic screening of 31 pure component working fluids for organic Rankine cycles [4]. Lai et al. considered alkanes, aromates, and linear siloxanes as working fluids for high-temperature organic Rankine cycles [5].

Many researchers have also investigated ORC system design and parametric optimization. Roy et al. conducted a parametric optimization and performance analysis of a waste-heat recovery system based on an organic Rankine cycle using R12, R123, and R134a as the working fluids for power generation [6]. Schuster presented a simulation study of an ORC when using supercritical 
parameters and various working fluids [7]. Teng et al. studied a supercritical organic Rankine cycle system for recovery of waste heat from heavy-duty diesel engines [8]. The performance of a novel, thermally activated system combining an ORC with a vapor compression cycle for vehicular engine waste-heat recovery was studied by Little and Garimella [9], Wang et al. [10], and Wang et al. [11]. Guo et al. investigated the performance of a novel cogeneration system that consisted of a low temperature, geothermallypowered ORC subsystem, an intermediate heat exchanger subsystem, and a heat pump subsystem [12,13]. Yamada et al. carried out a basic experiment using a new pumpless organic Rankine cycle for power generation from a low-temperature heat source [14]. Vaja and Gambarotta described a specific thermodynamic analysis in order to efficiently match an ORC to that of a stationary internal combustion engine. The analysis demonstrated that a $12 \%$ increase in the overall efficiency could be achieved with respect to the engine with no bottoming occurring [15]. Srinivasan et al. examined the exhaust waste-heat recovery potential of a high-efficiency, low-emissions, dual-fuel, lowtemperature combustion engine using an ORC. Results showed that fuel conversion efficiency improved by an average of 7 percent for all injection timings and loads with hot exhaust gas recirculation (EGR) and ORC turbocompounding [16]. Arias et al. presented a theoretical study of different waste-heat recovery strategies for an internal combustion engine operating in a hybrid vehicle [17]. While few of these investigations have concentrated on spark ignition engine applications, the auto company BMW has accomplished some pioneering research in this area, performing an analysis of the Rankine cycle as an additional power generation process using the waste heat of a car engine [18,19].

For this paper, a dual loop ORC system was designed which combines a high temperature (HT) loop and a low temperature (LT) loop to simultaneously recover the waste heat from the exhaust and the coolant of a gasoline engine. The HT loop only recovers the exhaust heat while the LT loop recovers both the residual HT loop heat and the coolant heat. The two separate loops are coupled with a preheater. The system structure is similar to that of BMW's design, but organic working fluids are substituted for water and ethanol as the working fluids. In order to evaluate the dual loop system performance when combined with a gasoline engine, the waste heat quantities were first calculated using engine test data. Based on these calculations, the working parameters for the HT and LT loops were configured and R245fa and R134a were selected as the working fluids for the HT loop and the LT loop. Finally, the performance map of the combined system was calculated and compared to a system with a non-bottoming ORC.

\section{System description}

When a gasoline engine is running, the energy and exergy quantities of the exhaust and the coolant are significantly different. Because of this, it is very difficult to design a system that can comprehensively recover waste heat from both the exhaust and the coolant of that system. Some previous designs have used the coolant heat to preheat the working fluid and the exhaust heat to evaporate and superheat the working fluid $[15,17,20]$. However, the heat addition quantity during the evaporating process is greater than that of the preheating process, whereas, the waste heat quantity of the coolant almost equals that of the exhaust. Therefore, the waste heat of the coolant is not comprehensively utilized.

The dual loop ORC designed for this study is shown in Fig. 1. A HT loop recovers the exhaust waste heat while a LT loop is coupled to recover the residual heat of the HT loop and the coolant waste heat. The HT loop consists of pump 1, evaporator 1, expander 1, the preheater, reservoir 1 , and the connecting pipes. The LT loop consists of pump 2, the preheater, evaporator 2, expander 2, the condenser, reservoir 2, and the connecting pipes. The LT loop is coupled with the HT loop via the preheater. In this design, a single screw expander is employed as the expander, which has better performance for small-scale applications [21]. The working fluid of the HT loop was chosen to be R245fa because of its good safety and environmental properties [22,23]. For the low-temperature ORC, on the other hand, using a zeotropic mixture as the working fluid can improve system performance [24,25]. However, R134a was selected

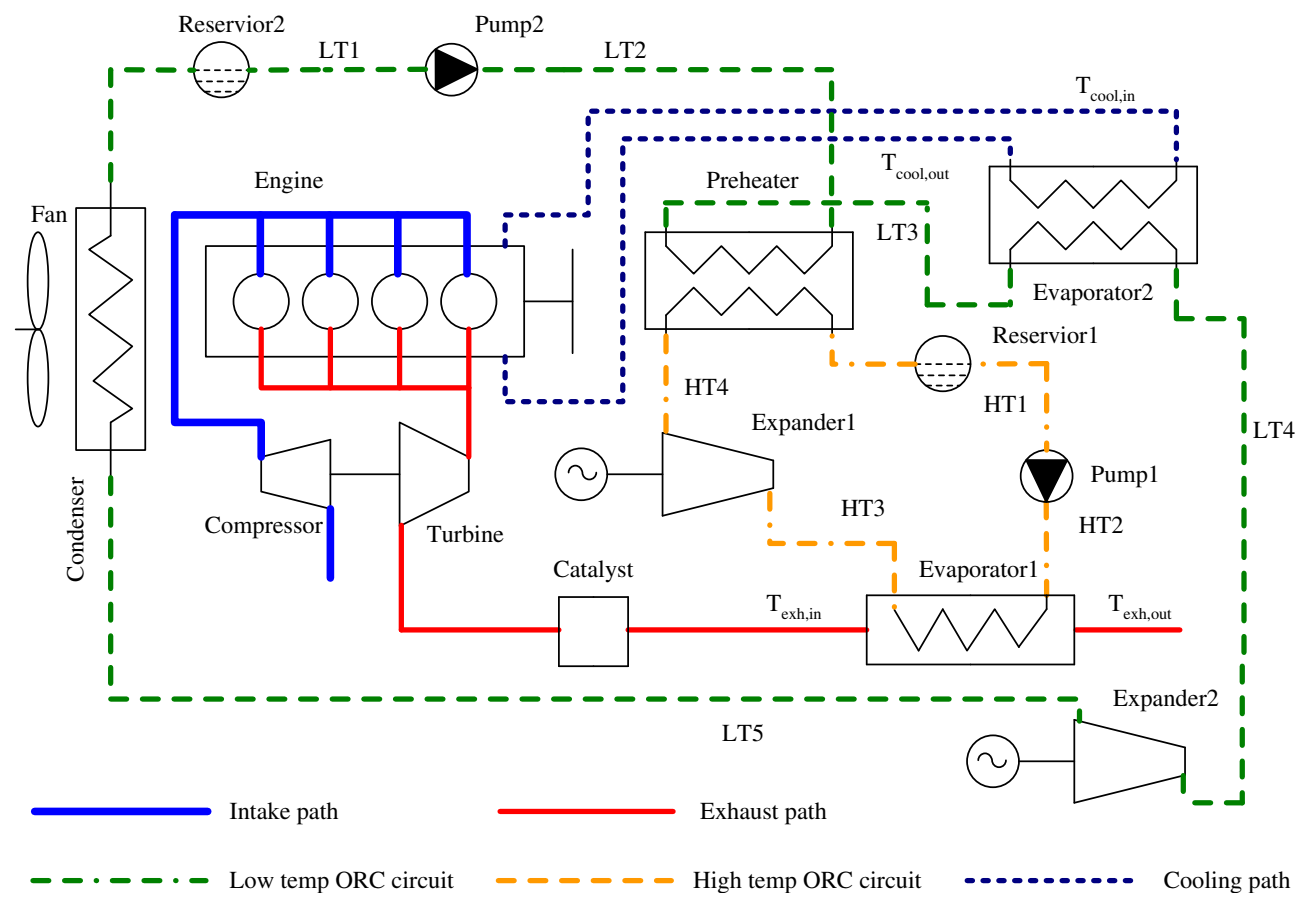

Fig. 1. Schematic of a dual loop ORC system combined with a gasoline engine. 
as the working fluid of the LT loop to facilitate the calculation process and minimize performance reduction [26]. R134a is also an environmentally friendly refrigerant, widely used in automotive air-conditioners. The properties of these two working fluids are listed in Table 1.

The working principle of the dual loop system is illustrated in Fig. 2. After a gasoline engine warms up, the ORC system starts to recover waste heat. $\mathrm{R} 245 \mathrm{fa}$ is pumped from reservoir 1 to evaporator 1, corresponding to the process HT1 to HT2. The waste heat from the exhaust is then added and the working fluid is evaporated to a saturated vapor state HT3. Subsequently, the R245fa is expanded in expander 1 and the useful work is output to generate electricity. R245fa is a dry working fluid; therefore, it changes to a superheated state HT4 after expansion [27]. In the preheater, R245fa is transformed into a saturated liquid state HT1 after transferring its heat to the R134a working fluid. Later, the working fluid returns to reservoir 1 and waits for the next circulation cycle. Meanwhile, in the LT loop, pump 2 pressurizes the R134a from reservoir 2 to the preheater. The corresponding process is shown as LT1 to LT2 in Fig. 2. The R134a is preheated to a two-phase state LT3 in the preheater. Then the coolant flows out of the engine jacket, evaporates, and heats the R134a to a superheated state LT4 in evaporator 2. Overheating is required because R134a is a wet working fluid and overheating guarantees that no liquid is generated during the subsequent expansion process. The R134a is situated at a slightly superheated state LT5 after expanding in expander 2. Later, the fluid is condensed to a saturated liquid state LT1 in the condenser and flows back to reservoir 2. The saturated curves of R245fa and R134a are plotted in the $T-s$ diagram of Fig. 2. The upper red lines correspond to the HT loop while the lower blue lines show the LT loop. Considering the influence of the pinch point temperatures, the maximum temperature of the R134a is $5{ }^{\circ} \mathrm{C}$ lower than the minimum temperature of the R245fa working fluid.

\section{Mathematical model}

The thermodynamic model for the system described in this paper is developed using the first and second laws methods. In the HT loop, process HT1 to HT2 is expressed as

$\dot{W}_{\mathrm{p} 1}=\dot{m}_{\mathrm{HT}}\left(h_{\mathrm{HT} 2}-h_{\mathrm{HT} 1}\right)=\dot{m}_{\mathrm{HT}}\left(h_{\mathrm{HT} 2 \mathrm{~s}}-h_{\mathrm{HT} 1}\right) / \eta_{\mathrm{p} 1}$

$\dot{I}_{\mathrm{p} 1}=T_{0} \dot{m}_{\mathrm{HT}}\left(s_{\mathrm{HT} 2}-s_{\mathrm{HT} 1}\right)$

where $\dot{W}_{\mathrm{p} 1}$ is the input work required by pump $1, \eta_{\mathrm{p} 1}$ is the isentropic efficiency of pump $1, \dot{I}_{\mathrm{p} 1}$ is the exergy destruction rate of pump $1, \dot{m}_{\mathrm{HT}}$ is the mass flow rate of the HT loop working fluid, $h$ is the specific enthalpy, $s$ is the specific entropy, and $T_{0}$ is the reference temperature.

The heat exchange process between the exhaust gas and the R245fa fluid in evaporator 1 is denoted as

$\dot{Q}_{\text {exh }}=\dot{m}_{\text {exh }}\left(h_{\text {exh,in }}-h_{\text {exh,out }}\right)$

$\dot{\mathrm{Q}}_{\mathrm{exh}}=\dot{m}_{\mathrm{HT}}\left(h_{\mathrm{HT} 3}-h_{\mathrm{HT} 2}\right)$

where $\dot{Q}_{\text {exh }}$ is the heat addition quantity, $\dot{m}_{\text {exh }}$ is the mass flow rate of the exhaust, and $T_{\text {exh,out }}$ is the exhaust temperature at the outlet

Table 1

Properties of the selected working fluids.

\begin{tabular}{lllll}
\hline Organic fluid & Molecular weight $[\mathrm{kg} / \mathrm{kmol}]$ & $T_{\mathrm{cr}}[\mathrm{K}]$ & $P_{\mathrm{cr}}[\mathrm{MPa}]$ & $T_{\mathrm{bp}}[\mathrm{K}]$ \\
\hline R245fa & 134.05 & 427.2 & 3.639 & 288.05 \\
R134a & 102.03 & 374.21 & 4.059 & 247.08 \\
\hline
\end{tabular}

of evaporator 1 . The exergy destruction rate in evaporator $1\left(\dot{I}_{\text {exh }}\right)$ is calculated as

$\dot{I}_{\mathrm{e} 1}=T_{0} \dot{m}_{\mathrm{HT}}\left(s_{\mathrm{HT} 3}-s_{\mathrm{HT} 2}\right)+T_{0} \dot{m}_{\mathrm{exh}}\left(s_{\text {exh,out }}-s_{\text {exh,in }}\right)$

The pinch method is used to analyze the heat exchange process in evaporator 1. According to the results published by Wang et al. [28], the pinch point is located at the inlet of the working fluid side of the evaporator. The temperature difference at the pinch point is set to $10 \mathrm{~K}$ for this study. Therefore, the exhaust temperature at the outlet of evaporator 1 is

$T_{\text {exh,out }}=T_{\mathrm{HT} 2}+10$

The exhaust temperature at the inlet of evaporator 1 is measured via an engine performance test. The enthalpy and entropy are calculated based on the ingredients and temperature of the exhaust. Thus, Eq. (3) provides the heat quantity transferred by the exhaust.

The output work done by expander 1 is calculated as

$\dot{W}_{\mathrm{s} 1}=\dot{m}_{\mathrm{HT}}\left(h_{\mathrm{HT} 3}-h_{\mathrm{HT} 4}\right)=\dot{m}_{\mathrm{HT}}\left(h_{\mathrm{HT} 3}-h_{\mathrm{HT} 4 \mathrm{~s}}\right) \eta_{\mathrm{s} 1}$

where $\eta_{\mathrm{s} 1}$ is the isentropic efficiency of expander 1 . The exergy destruction rate of expander $1\left(\dot{I}_{\mathrm{s} 1}\right)$ is expressed as

$\dot{I}_{\mathrm{s} 1}=T_{0} \dot{m}_{\mathrm{HT}}\left(s_{\mathrm{HT} 4}-s_{\mathrm{HT} 3}\right)$

The HT4 to HT1 process is denoted as

$\dot{Q}_{\text {pre }}=\dot{m}_{\mathrm{HT}}\left(h_{\mathrm{HT} 4}-h_{\mathrm{HT} 1}\right)$

where $\dot{Q}_{\text {pre }}$ is the heat rejection quantity of the R245fa working fluid during the condensation process. In the LT loop, the LT1 to LT2 process is expressed as

$\dot{W}_{\mathrm{p} 2}=\dot{m}_{\mathrm{LT}}\left(h_{\mathrm{LT} 2}-h_{\mathrm{LT} 1}\right)=\dot{m}_{\mathrm{LT}}\left(h_{\mathrm{LT} 2 \mathrm{~s}}-h_{\mathrm{LT} 1}\right) / \eta_{\mathrm{p} 2}$

where $\dot{W}_{\mathrm{p} 2}$ is the input work of pump 2, $\eta_{\mathrm{p} 2}$ is the isentropic efficiency of pump 2 , and $\dot{m}_{\mathrm{LT}}$ is the mass flow rate of the R134a. The exergy destruction rate of pump $2\left(\dot{I}_{\mathrm{p} 2}\right)$ is calculated as

$\dot{I}_{\mathrm{p} 2}=T_{0} \dot{m}_{\mathrm{LT}}\left(s_{\mathrm{LT} 2}-s_{\mathrm{LT} 1}\right)$

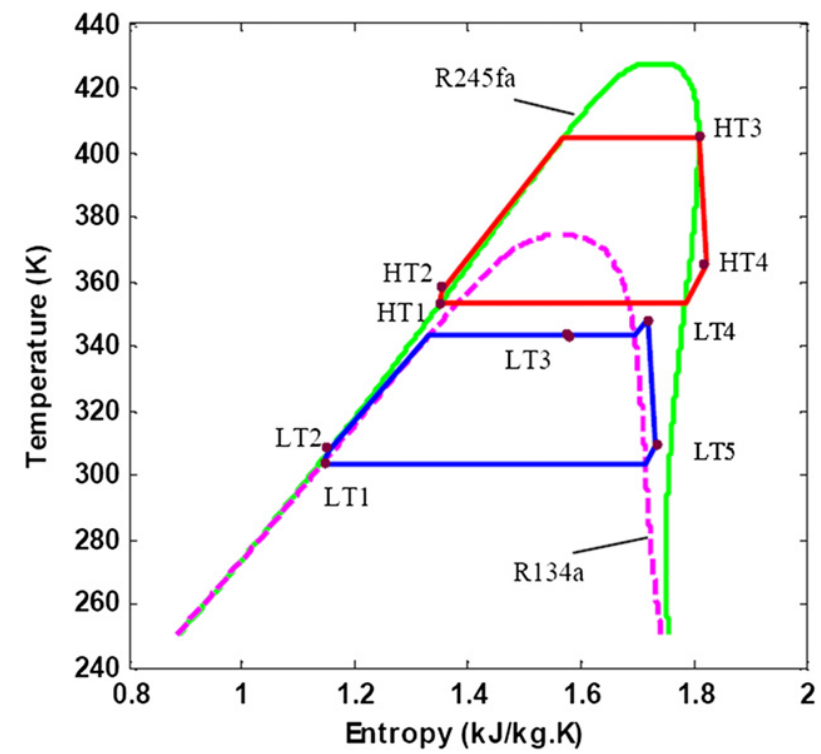

Fig. 2. $T-s$ plots of the HT and LT loops. (For interpretation of the references to color in this figure legend, the reader is referred to the web version of this article.) 
The heat addition quantity for the R134a in the preheater ( $\left.\dot{Q}_{\text {pre }}\right)$ is calculated as

$\dot{Q}_{\text {pre }}=\dot{m}_{\mathrm{LT}}\left(h_{\mathrm{LT} 3}-h_{\mathrm{LT} 2}\right)=\dot{m}_{\mathrm{HT}}\left(h_{\mathrm{HT} 4}-h_{\mathrm{HT} 1}\right)$

The exergy destruction rate in the preheater $\left(\dot{I}_{\text {pre }}\right)$ is computed as

$\dot{I}_{\text {pre }}=T_{0} \dot{m}_{\mathrm{HT}}\left(s_{\mathrm{HT} 1}-s_{\mathrm{HT} 4}\right)+T_{0} \dot{m}_{\mathrm{LT}}\left(s_{\mathrm{LT} 3}-s_{\mathrm{LT} 2}\right)$

and the heat addition quantity in evaporator $2\left(\dot{Q}_{\mathrm{e} 2}\right)$ is calculated as

$\dot{\mathrm{Q}}_{\mathrm{e} 2}=\dot{m}_{\mathrm{LT}}\left(h_{\mathrm{LT} 4}-h_{\mathrm{LT} 3}\right)$

Since this heat addition quantity is completely provided by the coolant waste heat, it can be represented by

$\dot{\mathrm{Q}}_{\mathrm{e} 2}=\dot{\mathrm{Q}}_{\mathrm{cool}}$

where $\dot{Q}_{\text {cool }}$ is the heat quantity rejected by the coolant. Like the exhaust temperature, this value can be measured via an engine performance test, along with the coolant temperatures and pressures at the inlet and outlet of evaporator 2 , namely $T_{\text {cool,in }}, T_{\text {cool,out, }}$, $P_{\text {cool,in, }}$ and $P_{\text {cool,out. }}$ Therefore, the corresponding specific enthalpies $h_{\text {cool,in }}$ and $h_{\text {cool,out }}$ can be calculated. Moreover, the mass flow rate of the coolant $\left(\dot{m}_{\text {cool }}\right)$ can be estimated as

$\dot{m}_{\text {cool }}=\frac{\dot{Q}_{\text {cool }}}{\left(h_{\text {cool, in }}-h_{\text {cool }, \text { out }}\right)}$

and the exergy destruction rate in evaporator $2\left(\dot{I}_{\mathrm{e} 2}\right)$ becomes

$\dot{I}_{\mathrm{e} 2}=T_{0} \dot{m}_{\mathrm{LT}}\left(s_{\mathrm{LT} 4}-s_{\mathrm{LT} 3}\right)+T_{0} \dot{m}_{\text {cool }}\left(s_{\text {cool, out }}-s_{\text {cool, in }}\right)$

To maintain a smooth heat transmission from the high temperature side to the low temperature side, the temperature difference between the condensation temperature of the HT loop and the maximum temperature of the LT loop was set to $5 \mathrm{~K}$. For this analysis, this means the working fluid temperature at state LT4 $\left(T_{\mathrm{LT} 4}\right)$ can be described as

$T_{\mathrm{LT} 4}=T_{\mathrm{HT} 1}-5$

where $T_{\mathrm{HT} 1}$ is the temperature of the R245fa working fluid at state HT1. To maintain the working fluid in a superheated gas state during the expansion process in expander 2, the temperature of the $\mathrm{R} 134 \mathrm{a}$ at state LT4 is configured as

$T_{\mathrm{LT} 4}=T_{\mathrm{LTb}}+5$

where $T_{\mathrm{LTb}}$ is the evaporation temperature of the R134a under the same pressure as experienced in state LT4. The output work generated by expander $2\left(\dot{W}_{\mathrm{s} 2}\right)$ is expressed as

$\dot{W}_{\mathrm{s} 2}=\dot{m}_{\mathrm{LT}}\left(h_{\mathrm{LT} 4}-h_{\mathrm{LT} 5}\right)=\dot{m}_{\mathrm{LT}}\left(h_{\mathrm{HT} 4}-h_{\mathrm{LT} 5 \mathrm{~s}}\right) \eta_{\mathrm{s} 2}$

where $\eta_{\mathrm{s} 2}$ is the isentropic efficiency of expander 2. The exergy destruction rate of expander $2\left(\dot{I}_{\mathrm{s} 2}\right)$ is expressed as

$\dot{I}_{\mathrm{S} 2}=T_{0} \dot{m}_{\mathrm{LT}}\left(s_{\mathrm{LT} 5}-s_{\mathrm{LT} 4}\right)$

The heat rejection quantity of the R134a working fluid in the condenser $\left(\dot{Q}_{c}\right)$ is calculated as

$\dot{Q}_{\mathrm{c}}=\dot{m}_{\mathrm{LT}}\left(h_{\mathrm{LT} 5}-h_{\mathrm{LT} 1}\right)$

If the mean temperature of the R134a in the condenser $\left(T_{\mathrm{mc}}\right)$ is assumed to be equal to the condensation temperature, the exergy destruction rate of the condenser becomes
$\dot{I}_{\mathrm{c}}=T_{0} \dot{m}_{\mathrm{LT}}\left[\left(s_{\mathrm{LT} 1}-s_{\mathrm{LT} 5}\right)-\frac{h_{\mathrm{LT} 1}-h_{\mathrm{LT} 5}}{T_{\mathrm{mc}}}\right]$

Given the operating conditions of a dual loop ORC system assembled on a vehicle, the following are the assumptions for the thermodynamic model used in this paper:

(1) All the cycles operated in a steady state.

(2) The expander 1 inlet pressure was set to $2.4 \mathrm{MPa}$.

(3) The condensation temperature of R245fa was set to $80^{\circ} \mathrm{C}$. The evaporation temperature of the R134a was $70{ }^{\circ} \mathrm{C}$ according to Eqs. (18) and (19). Since the opening temperature of an engine thermostat valve is normally set to $90{ }^{\circ} \mathrm{C}$, the minimum temperature difference between the coolant and the R134a was $15{ }^{\circ} \mathrm{C}$. Therefore, this temperature configuration is plausible when considering the temperature limitation at the pinch point.

(4) The condensation temperature of the R134a was set to $30^{\circ} \mathrm{C}$.

(5) The pressure loss and heat rejection of the pipes was ignored.

(6) The isentropic efficiency of pump 1 and pump 2 was set to 0.8 .

(7) The isentropic efficiency of expander 1 and expander 2 was set to 0.75 .

\section{Engine waste heat evaluation}

To evaluate the dual loop ORC system performance, we first obtained the waste heat quantities of the exhaust and coolant systems of the gasoline engine. In this research, a four cylinder turbocharged gasoline engine was selected as the case study. Table 2 lists the main specifications for this engine.

When a vehicle is running, the engine speed and load can vary through a wide range. Therefore, the engine performance test was conducted in an engine test cell in order to obtain the thermodynamic parameters of the exhaust and coolant systems overall possible engine operating regions as defined by the engine speed and output torque. The engine test cell integrated with all the measuring equipments was designed by FEV Co., Ltd. and delivered to Shengyang Brilliance Co., Ltd. for new engine development. The test procedure was performed according to Ref. [29]. For our measurements, the minimal and maximal engine speeds were set to $1000 \mathrm{r} / \mathrm{min}$ and $5900 \mathrm{r} / \mathrm{min}$, respectively. The intermediate speeds were selected using a step increment of $500 \mathrm{r} / \mathrm{min}$, starting from the minimum engine speed. At each selected engine speed, eight different load values were selected, ranging from a $100 \%$ load to a minimal stable load value. The values for the output torque, the output power, the engine speed, the mass flow rate of the intake air, the injected fuel quantity, the exhaust gas temperature, and the coolant temperatures at the outlet of the engine's water jacket were all recorded for each load and speed configuration.

One common way to present the operating characteristics of an internal combustion engine over its full load and speed range is to plot brake specific fuel consumption contours on a graph of brake

Table 2

Specifications of the BL18T gasoline engine.

\begin{tabular}{lll}
\hline Item & Parameter & Unit \\
\hline Model & BL18T & - \\
Displacement & 1.793 & $\mathrm{~L}$ \\
Bore $\times$ stroke & $81 \times 87$ & $\mathrm{~mm}$ \\
Cylinder number & 4 & - \\
Valve number per cylinder & 4 & - \\
Fuel injection equipment & Multi-point sequence injection & - \\
Rated power & 130 & $\mathrm{~kW}$ \\
Rated speed & 5900 & $\mathrm{r} / \mathrm{min}$ \\
Max. torque & 235 & $\mathrm{~N} \mathrm{~m}$ \\
Speed at max. torque & $2500-5000$ & $\mathrm{r} / \mathrm{min}$ \\
\hline
\end{tabular}


mean effective pressure (or engine torque) versus engine speed $[30,31]$. The measured engine performance map is displayed in Fig. 3a. The contours with red lines represent the measured engine power $(\mathrm{kW})$, which are also used in the following figures. The colorfilled contours with black lines denote the variable shown in the upper of the figure. The lowest brake specific fuel consumption (b.s.f.c.) zone is situated at the high duty range between $2000 \mathrm{r} / \mathrm{min}$ and $4000 \mathrm{r} / \mathrm{min}$ and the minimum b.s.f.c. value is less than $242 \mathrm{~g} /$ $\mathrm{kWh}$. The maximal output torque on the external characteristic profile maintains an almost horizontal line for engine speeds between $2000 \mathrm{r} / \mathrm{min}$ and $5000 \mathrm{r} / \mathrm{min}$, which contributes to a vehicle's drivability. The effective thermal efficiency is defined as the ratio of the output torque at the flywheel end to the fuel combustion energy [30], and the results are given in Fig. 3b. The effective thermal efficiency reaches a peak of greater than $40 \%$ in the low b.s.f.c. region. Fig. $3 c$ shows the measured exhaust temperature. The temperature is above $600 \mathrm{~K}$ over the engine's entire working region, and increases with engine speed and engine load. The exhaust temperature is $1056.8 \mathrm{~K}$ at the rated power point. Fig. $3 \mathrm{~d}$ shows the mass flow rate of the exhaust, which is the sum of the intake air amount and the injected fuel quantity. The exhaust mass flow rate decreases linearly with the engine output power and the maximal mass flow rate is $0.1615 \mathrm{~kg} / \mathrm{s}$ at the rated power point.

The waste heat quantity of the gasoline engine was then evaluated using the measured engine operating parameters. Eq. (24) describes the fuel combustion process according to the conservation of energy

$\dot{m}_{\mathrm{f}} h_{\mathrm{f}}+\dot{m}_{\mathrm{a}} h_{\mathrm{a}}=\dot{W}_{\mathrm{b}}+\dot{Q}_{\text {cool }}+\dot{Q}_{\text {misc }}+\dot{m}_{\mathrm{exh}} h_{\text {exh }}$

Here, $\dot{m}_{\mathrm{f}}$ and $\dot{m}_{\mathrm{a}}$ are the fuel and air mass flow rates, respectively, $h_{\mathrm{f}}$ and $h_{\mathrm{a}}$ are the corresponding inlet enthalpies, $\dot{W}_{\mathrm{b}}$ is the shaft power of the engine (i.e. the useful brake power), $\dot{Q}_{\text {cool }}$ is the heat transferred to the cooling system, and $\dot{Q}_{\text {misc }}$ is the miscellaneous heat loss due to heat conduction to the oil, convection, and radiation from the engine block. The combustion energy (defined as the enthalpy of the flammable mixture of gases) is calculated from the injected fuel quantity and the intake air mass. While the miscellaneous heat loss normally accounts for $3-10 \%$ of the overall combustion energy of a gasoline engine, a fixed $8 \%$ was used in this study. The exhaust enthalpy was calculated using an approximation method. Isooctane was assumed to be the gasoline fuel. The AFR (air-fuel ratio) of a modern gasoline engine is controlled to a stoichiometric ratio to maintain a high efficiency of the three-way catalytic converter. Therefore, the chemical reaction equation for the combustion process is

$\mathrm{C}_{8} \mathrm{H}_{18}+12.5\left(\mathrm{O}_{2}+3.76 \mathrm{~N}_{2}\right) \rightarrow 8 \mathrm{CO}_{2}+9 \mathrm{H}_{2} \mathrm{O}+47 \mathrm{~N}_{2}$

The other substances contained in the exhaust gas were ignored for this study. Therefore, the results for the mass fractions of $\mathrm{CO}_{2}$, $\mathrm{H}_{2} \mathrm{O}$, and $\mathrm{N}_{2}$ were

$x_{\mathrm{CO}_{2}}=0.1923$
$x_{\mathrm{H}_{2} \mathrm{O}}=0.08854$
$x_{\mathrm{N}_{2}}=0.7192$
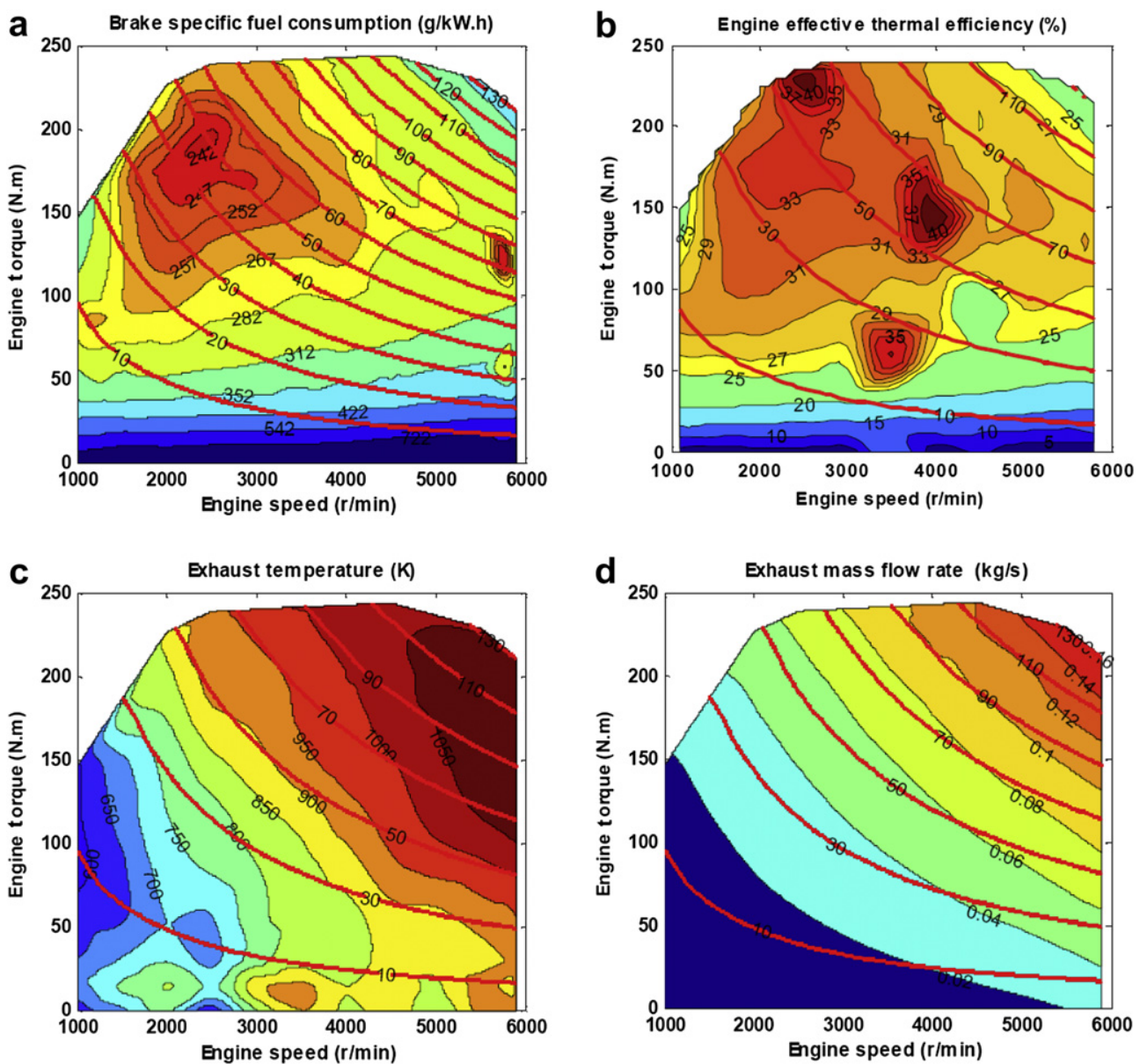

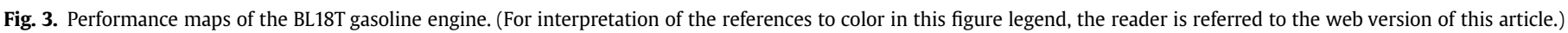


The specific enthalpy of the exhaust gas under a specific temperature $(T)$ is calculated using the method for a mixture of gases [32]

$h_{\mathrm{exh}}(T)=x_{\mathrm{CO}_{2}} h_{\mathrm{CO}_{2}}(T)+x_{\mathrm{H}_{2} \mathrm{O}} h_{\mathrm{H}_{2} \mathrm{O}}(T)+x_{\mathrm{N}_{2}} h_{\mathrm{N}_{2}}(T)$

Finally, the waste heat quantity carried by the exhaust $\left(\dot{Q}_{\text {exh }}\right)$ can be calculated using Eq. (3). In addition, the waste heat quantity carried by the coolant $\left(\dot{Q}_{\text {cool }}\right)$ can be calculated using Eq. (24).

The waste heat quantities of the exhaust and the coolant were evaluated at each working point in the engine's entire operating region using the method outlined above. Fig. 4a gives the combustion energy and the heat energy brought by the exhaust is shown in Fig. 4b. The heat energy wasted by the coolant is given in Fig. 4c. The combustion energy increases almost linearly with the engine output power, achieving $613 \mathrm{~kW}$ at the rated power point. Note that the waste heat quantities of the exhaust and the coolant vary in a similar fashion. The reason is that the output power of a gasoline engine is proportional to the mass of the flammable mixtures. The comparison of these different energies is shown in Fig. $4 \mathrm{~d}$. The combustion energy is significantly larger than the output power for the engine's entire operating region. In particular, the combustion energy increases rapidly with the output power in the mediate and large load operating regions. The waste heat quantity of the coolant is less than that of the exhaust, but is also greater than the output power. The discrepancy is small in most of the engine's operating region, except for the region close to the rated power point.

\section{Combined system performance analysis}

After evaluating the waste heat quantities for the exhaust and coolant systems, the performance of the dual loop ORC system was analyzed at each measured engine operating point using the established mathematical model. The analysis program was written in Matlab [33] and the properties of the working fluids were computed by REFPROP 8.0, a program developed by the National Institute of Standards and Technology of the United States [34]. First, the exhaust mass flow rate $\left(\dot{m}_{\text {exh }}\right)$ and temperature $\left(T_{\text {exh,in }}\right)$ were obtained from the previous calculation process. The exhaust temperature at the outlet of evaporator 1 ( $\left.T_{\text {exh,out }}\right)$ was then computed using Eq. (6) and the heat quantity exchanged in evaporator 1 was calculated according to Eq. (3). Subsequently, the mass flow rate of the R245fa was computed using Eq. (4), along with the energy load for each component in the HT loop. The net output power of the HT loop $\left(\dot{W}_{\mathrm{n}, \mathrm{HT}}\right)$ was calculated using

$\dot{W}_{\mathrm{n}, \mathrm{HT}}=\dot{W}_{\mathrm{s} 1}-\dot{W}_{\mathrm{p} 1}$

Next, the heat rejection quantity of the R245fa working fluid in the preheater was determined and the mass flow rate of the R134a was calculated using Eqs. (12) and (14). Finally, the energy load for each component of the LT loop was calculated, giving the net power output of the LT loop $\left(\dot{W}_{\mathrm{n}, \mathrm{LT}}\right)$ through

$\dot{W}_{\mathrm{n}, \mathrm{LT}}=\dot{W}_{\mathrm{s} 2}-\dot{W}_{\mathrm{p} 2}$

The results for the thermodynamic properties of the working fluids, where the engine is operating at the rated power, are given in Table 3 and the energy load and the exergy destruction rate are
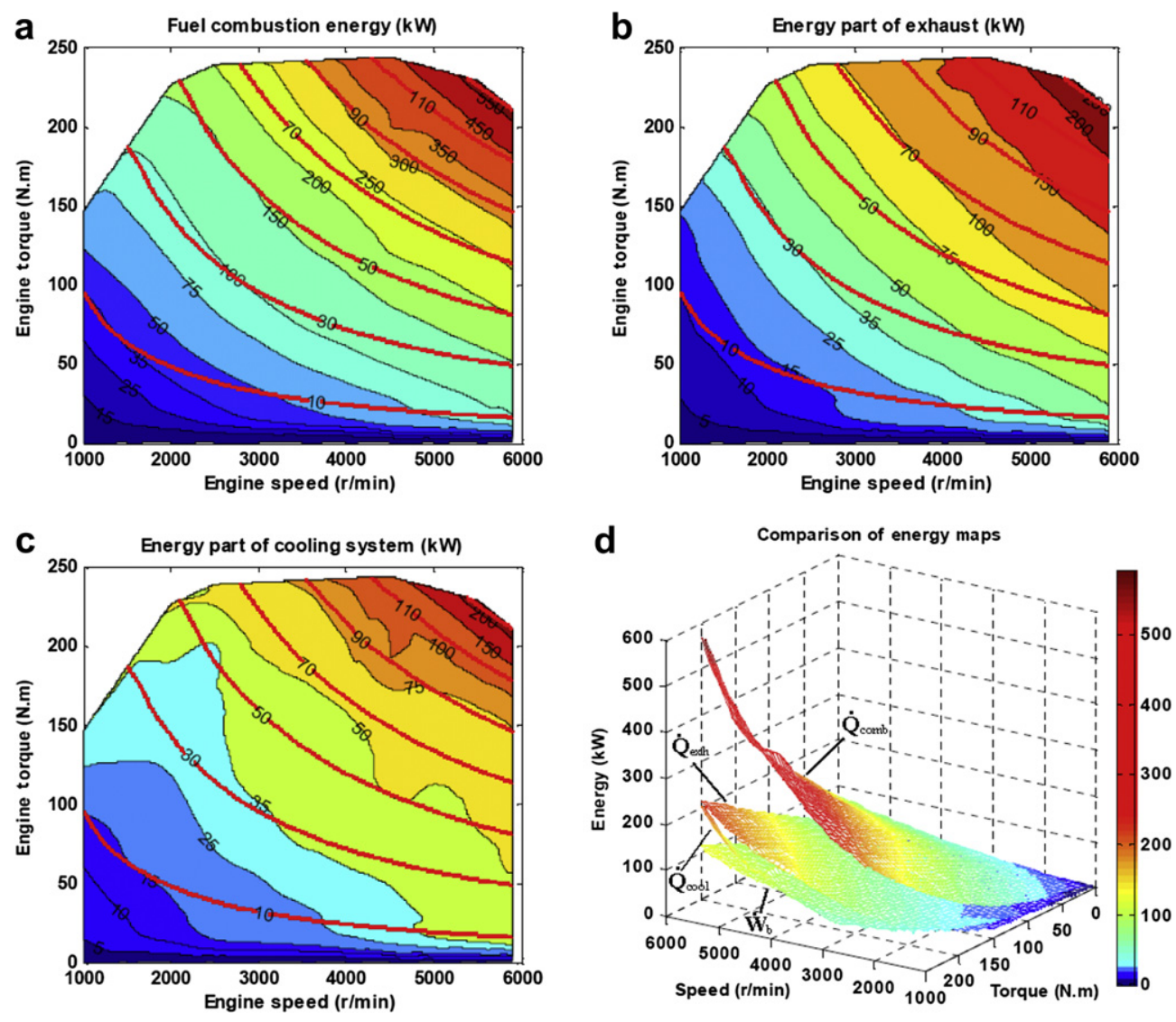

Fig. 4. Waste heat quantity characteristics. 
listed in Table 4. The performance map for the HT loop is shown in Fig. 5. And the mass flow rate of the R245fa is given in Fig. 5a. The results show that the maximal mass flow rate is $0.745 \mathrm{~kg} / \mathrm{s}$ at the rated engine power point and that the mass flow rate decreases almost linearly with the engine output power. The net output power of the HT loop is given in Fig. 5b, and shows that the maximal net power output is $9.573 \mathrm{~kW}$ at the rated engine power point. Note that the rate changes in Fig. 5a and b are very similar to the rate change in Fig. $4 \mathrm{~b}$ because the mass flow rate and net output power are proportional to the heat quantity exchanged in evaporator 1.

The performance map for the LT loop is displayed in Fig. 6 and the mass flow rate of the R134a is given in Fig. 6a. The results show that the maximal mass flow rate is $1.891 \mathrm{~kg} / \mathrm{s}$ at the rated engine power point, 2.54 times that of the maximal flow rate in the HT loop. The mass flow rate also linearly decreases with the engine output power. Fig. $6 \mathrm{~b}$ shows the net output power of the LT loop. The maximal net power output is $26.390 \mathrm{~kW}$ at the rated engine power point, 2.76 times larger than the maximal net power output of the HT loop. The net output power decreases almost linearly with the engine output power. The heat addition quantity of the LT loop is significantly larger than that of the HT loop because the LT loop absorbs the waste heat from the coolant and the heat rejected from the HT loop. At the rated power point, the heat addition quantity of the HT loop is $133 \mathrm{~kW}$, whereas the LT loop is $365 \mathrm{~kW}$. Also, the thermal efficiency of the HT loop is $7.16 \%$, slightly lower than that of the LT loop (7.72\%). Therefore, the LT loop performance is better than that of the HT loop.

The performance map of the combined engine-ORC system was then evaluated after the HT and LT loops were analyzed. Fig. 7 provides the overall net power map of the dual loop ORC system, and shows that the overall net power decreases linearly with engine power. The maximal overall net power is $35.96 \mathrm{~kW}$ at the rated power point, which improves the output power by $27 \%$ relative to the system without the dual loop ORC. The power augmentation of the combined system over the engine's entire working region is displayed in Fig. 8. In the small b.s.f.c. region, the augmentation proportion is lowest $(14-16 \%)$ because the waste heat quantity ratios of the exhaust and the coolant are lower. The reason for this is better fuel combustion effects, the engine pumping loss is lower, and the ratio of the output power to the combustion energy is higher than in other regions. In the small load region, the augmentation proportion is at its peak (35-46\%) because of the thermal inertia of the engine body and the coolant.

Fig. 9 shows the effective thermal efficiency map of the combined system. The effective thermal efficiency of a gasoline engine $\eta_{\mathrm{g}, \text { eff }}$ is calculated as

$\eta_{\mathrm{g}, \mathrm{eff}}=\frac{\dot{W}_{\mathrm{b}}}{\dot{Q}_{\mathrm{comb}}} \times 100 \%$

Table 3

Thermodynamic properties of the working fluids at the rated engine power.

\begin{tabular}{llllll}
\hline Cycles & State no. & $\begin{array}{l}\text { Pressure } \\
(\mathrm{MPa})\end{array}$ & $\begin{array}{l}\text { Temperature } \\
(\mathrm{K})\end{array}$ & $\begin{array}{l}\text { Enthalpy } \\
(\mathrm{kJ} / \mathrm{kg})\end{array}$ & $\begin{array}{l}\text { Entropy } \\
(\mathrm{kJ} / \mathrm{kg} \mathrm{K})\end{array}$ \\
\hline HT ORC & 1 & 0.789 & 353.15 & 310.51 & 1.352 \\
& 2 & 2.4 & 354.38 & 312.22 & 1.353 \\
& 3 & 2.4 & 404.59 & 491.58 & 1.809 \\
LT ORC & 4 & 0.789 & 365.01 & 477.01 & 1.823 \\
& 1 & 0.770 & 303.15 & 241.72 & 1.144 \\
& 2 & 2.117 & 304.15 & 243.14 & 1.144 \\
& $\mathrm{a}$ & 2.117 & 343.15 & 304.28 & 1.333 \\
& 3 & 2.117 & 343.15 & 308.70 & 1.346 \\
& $\mathrm{~b}$ & 2.117 & 343.15 & 428.65 & 1.696 \\
& 4 & 2.117 & 348.15 & 436.26 & 1.718 \\
& 5 & 0.770 & 308.93 & 420.89 & 1.734 \\
\hline
\end{tabular}

Table 4

Results of energy loads and exergy destruction rates at the rated engine power

\begin{tabular}{lcc}
\hline Subsystems & $\dot{E}(\mathrm{~kW})$ & $\dot{I}(\mathrm{~kW})$ \\
\hline Pump 1 & 1.277 & 0.721 \\
Evaporator 1 & 133.58 & 37.534 \\
Expander 1 & 10.851 & 9.969 \\
Preheater & 124.00 & 8.5375 \\
Pump 2 & 2.675 & 1.7593 \\
Evaporator 2 & 241.24 & 9.6412 \\
Expander 2 & 29.064 & 31.6118 \\
Condenser & 338.86 & 0.5308 \\
\hline
\end{tabular}

and the effective thermal efficiency of the combined system $\eta_{\mathrm{cs}, \text { eff }}$ is defined as

$\eta_{\mathrm{cs}, \mathrm{eff}}=\frac{\dot{W}_{\mathrm{b}}+\dot{W}_{\mathrm{n}, \mathrm{HT}}+\dot{W}_{\mathrm{n}, \mathrm{LT}}}{\dot{Q}_{\mathrm{comb}}} \times 100 \%$
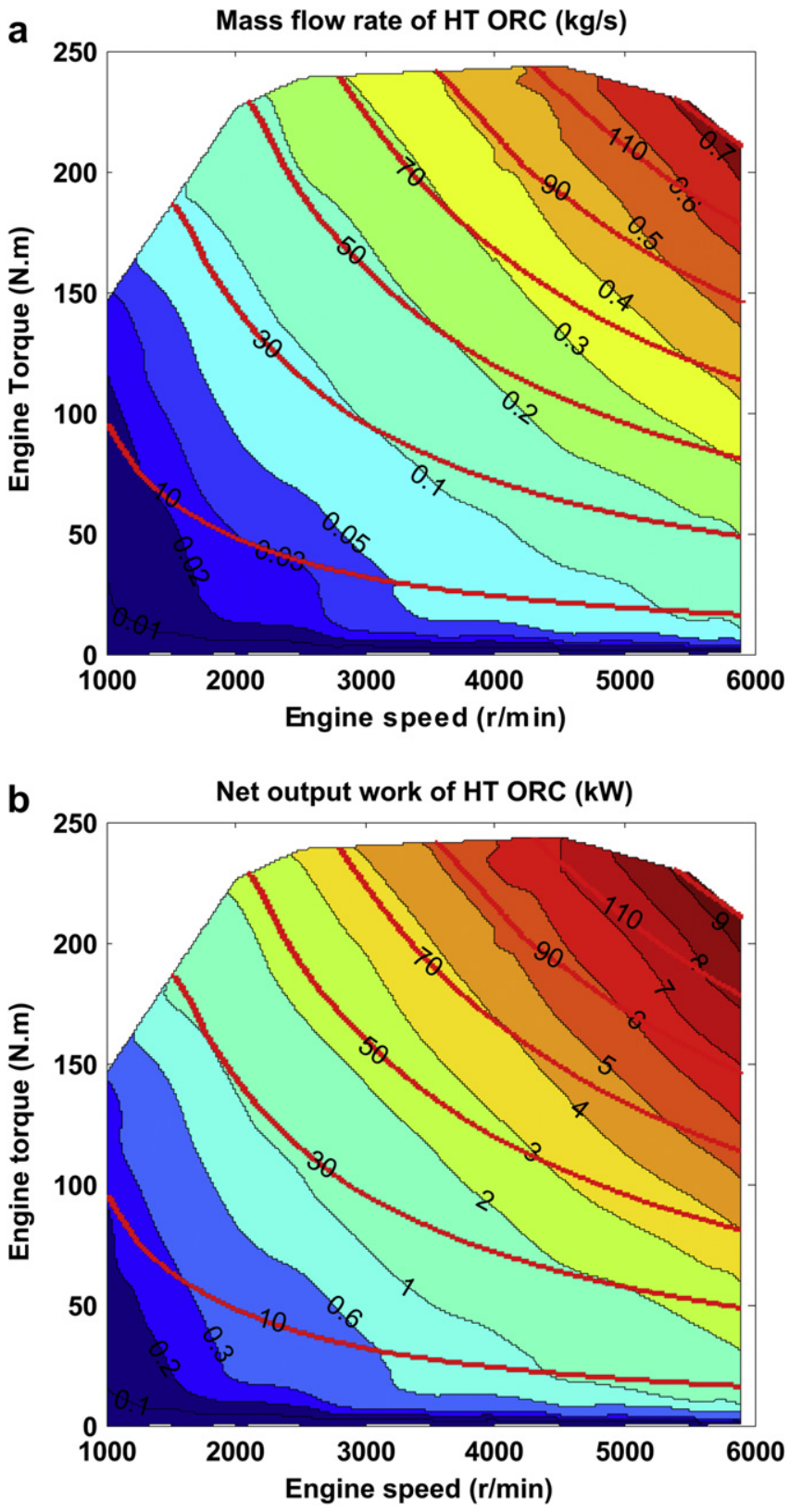

Fig. 5. Performance map of the HT loop. 

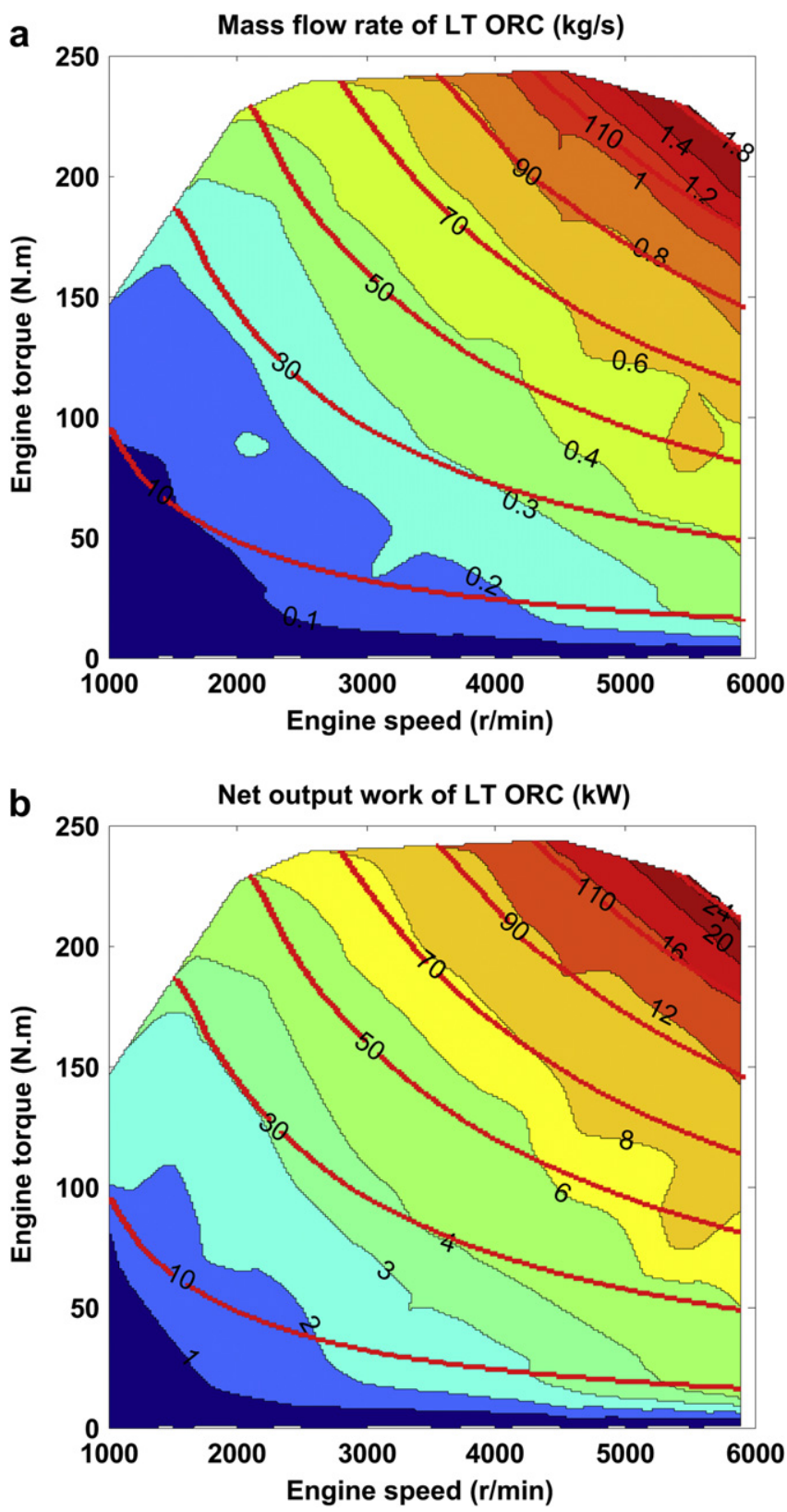

Fig. 6. Performance map of the LT loop.

The relative augmentation of the effective thermal efficiency is given in Fig. 10. In the peak effective thermal efficiency region, the augmentation ratio is between $14 \%$ and $16 \%$, whereas this ratio reaches $30-50 \%$ in the small load region for the same reasons that the power augmentation is highest in this region.

The exergy destruction rate of the combined system was also calculated and compared to a system without bottoming when the engine was operating along the external characteristic curve using the second law method. Exergy (also called availability) is the maximum useful work that can be obtained from a system at a given state in a specified environment [35,36]. Ignoring any changes in the kinetic and potential energy of the working fluid during the process, the exergy $(E)$ can be defined as

$E=H-H_{0}+T_{0}\left(s-s_{0}\right)$

where $H$ is the working fluid enthalpy, $H_{0}$ and $s_{0}$ are the enthalpy and entropy of the working fluid at its dead state, and $T_{0}$ is the

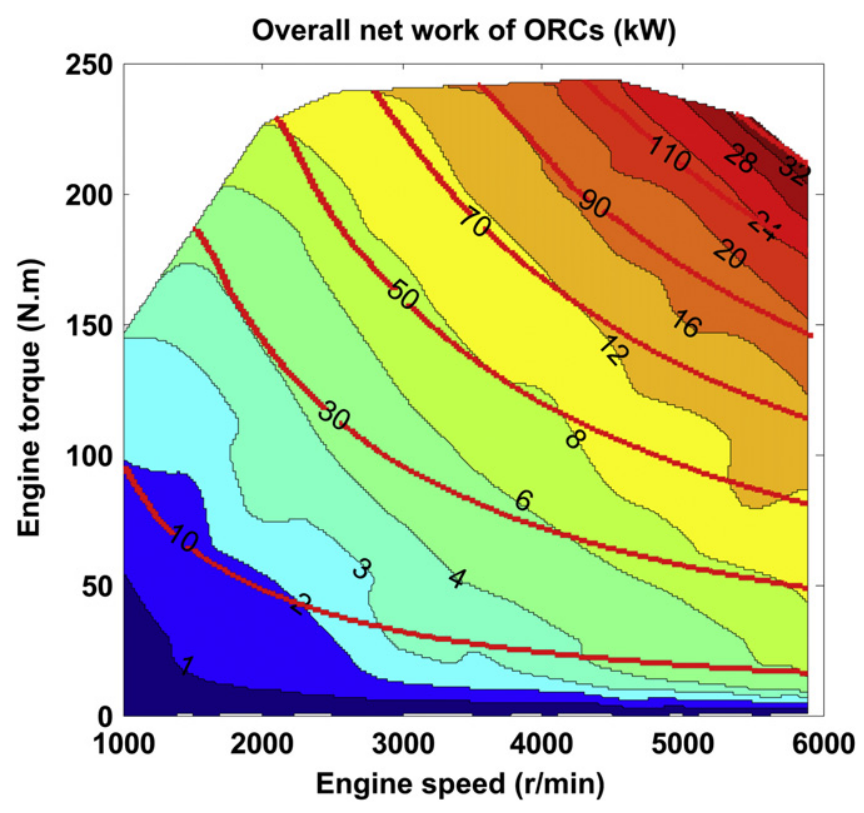

Fig. 7. Performance map of the overall net power for the dual loop system.

reference temperature at the dead state. For this study, the reference temperature was set to $0{ }^{\circ} \mathrm{C}$. According to the calculation of the exergy of heat available at a given temperature, the exergy content of the exhaust is expressed as

$E_{\mathrm{exh}}=\left(1-\frac{T_{0}}{T_{\mathrm{exh}}}\right) Q_{\mathrm{exh}}^{\prime}$

where $T_{\text {exh }}$ is the exhaust temperature and $Q_{\text {exh }}^{\prime}$ is the heat rejection quantity of the working fluid from $T_{\text {exh }}$ to $T_{0}$. The exergy content of the coolant is described as

$E_{\text {cool }}=\left(1-\frac{T_{0}}{T_{\text {cool }}}\right) Q_{\text {cool }}^{\prime}$

Fig. 11 gives the calculation results for the exergy content of the exhaust and the coolant, which shows that the exhaust exergy is

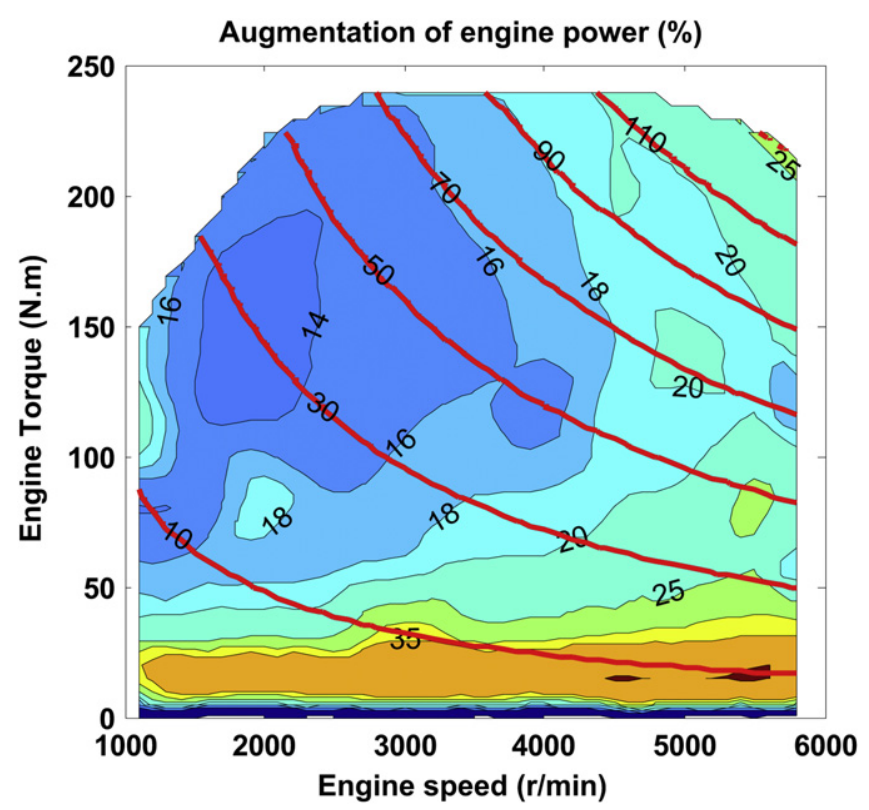

Fig. 8. Augmentation proportion of the output power with regard to the BL18T engine 


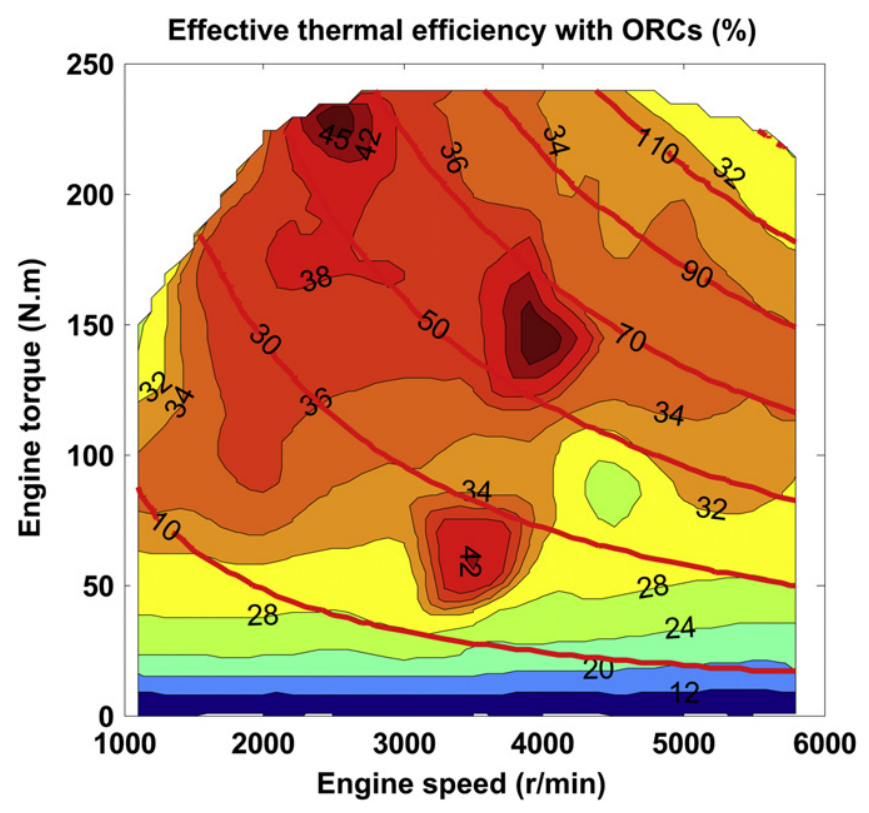

Fig. 9. Performance map of the effective thermal efficiency of the combined system.

larger than the coolant exergy when the engine speed is greater than $1200 \mathrm{r} / \mathrm{min}$. This difference increases with engine speed. The exhaust exergy is nearly two times larger than that of the coolant exergy because the exhaust temperature significantly increases with any increase in engine speed. The coolant exergy is larger than that of the exhaust exergy when the engine speed is below $1200 \mathrm{r} /$ min because of the thermal inertia of the coolant.

The results of the exergy analysis for the combined system, with the engine operating along the external characteristic curve, are provided in Fig. 12. The results show that the exhaust exergy significantly decreases after passing evaporator 1 because the exhaust temperature at the outlet is close to the reference temperature. The coolant exergy diminishes by about $40 \%$ after

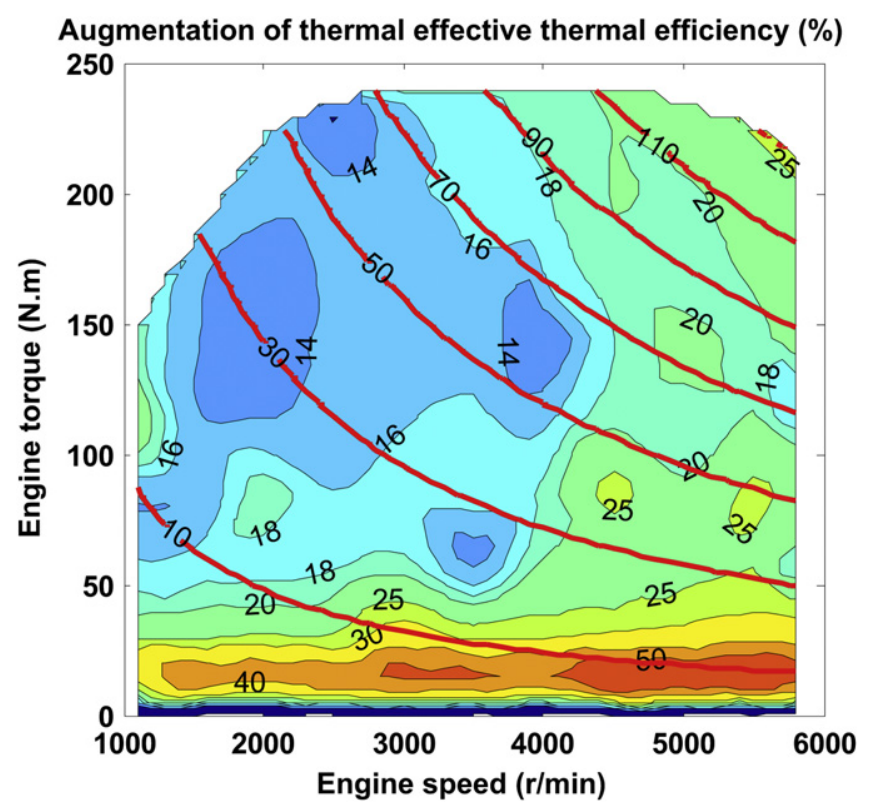

Fig. 10. Augmentation proportion of the effective thermal efficiency with regard to the BL18T engine.

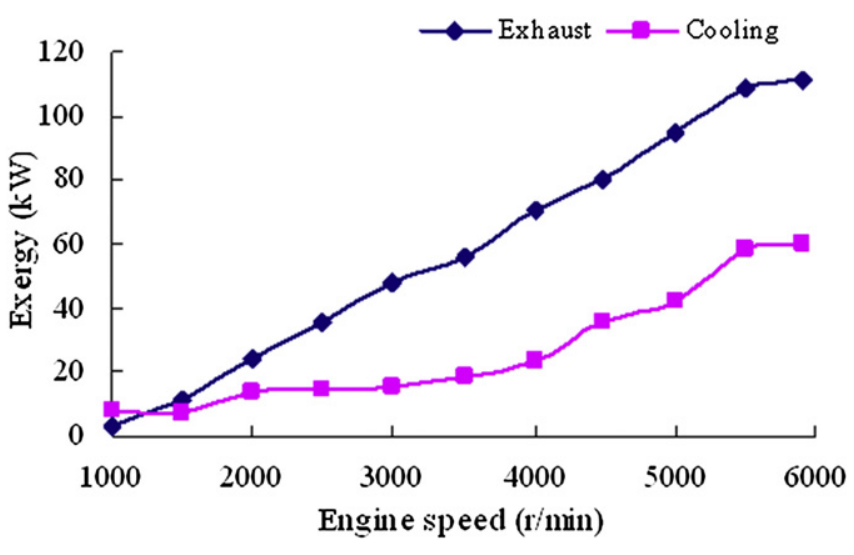

Fig. 11. Exergy of the waste heat for the BL18T engine at full load.

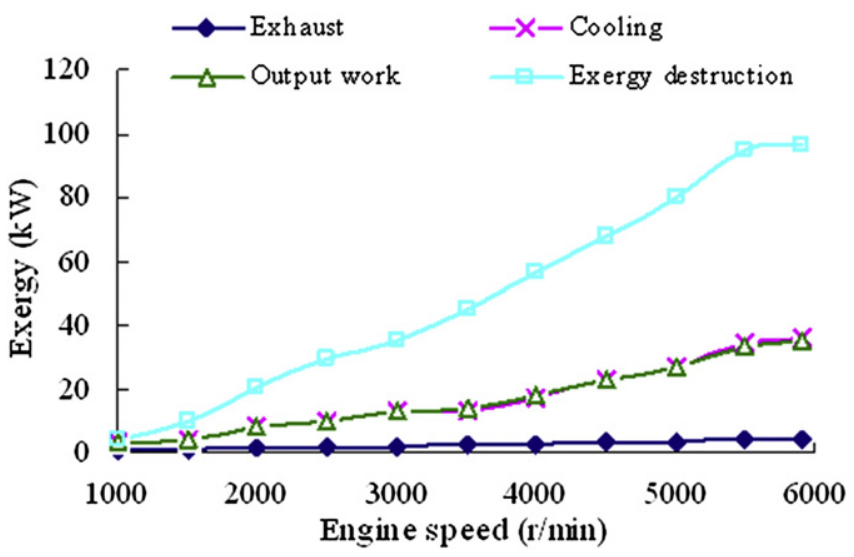

Fig. 12. Exergy analysis results for the combined system at full engine load.

rejecting heat in evaporator 2 . The change in the coolant exergy is lower than that seen for the exhaust exergy because the temperature difference in the coolant before and after evaporator 2 is within $10^{\circ} \mathrm{C}$. The exergy destruction rate of the combined system is very high, approaching the exhaust exergy in Fig. 11. This is because the thermal efficiency of the dual loop ORC system is only about $7 \%$ and there is lots of heat wasted during the condensation process in the condenser of the LT loop. If the thermal efficiency is improved, or the waste heat quantity in the condenser is reduced, the exergy destruction rate can be further decreased. The output power of the dual loop ORC increases with the engine speed. The similar trend can be seen on the coolant exergy. The values of these two variables are very close to each other. The reason can be explained as follows. The output power of the HT loop is proportional to the exhaust energy while the LT loop is a linear function of the exhaust and coolant energy. Meanwhile, the coolant exergy is proportional to the coolant mass flow rate (or the waste heat quantities carried away by the cooling system) when the coolant temperature keeps almost constant. According to the mathematical model and the experimental conditions, the results of the output power and coolant exergy are both shown a linear relationship with the total waste heat energy.

\section{Conclusions}

In this study, the waste heat quantities of the exhaust and coolant systems of a BL18T gasoline engine were analyzed using measured data. A novel dual loop ORC system was designed to 
recover the waste heat from the exhaust and the coolant. The performance map of the combined system was evaluated over the engine's entire operating region. Based on our analysis, we conclude the following:

1. The combustion energy is much greater than the output power through most of the operating region. The coolant heat quantity is slightly higher than the output power, but less than that of the exhaust.

2. A dual loop ORC system was designed to recover these two distinct waste heats at the same time. A HT loop recovers the exhaust waste heat using R245fa as the working fluid. A LT loop recovers the coolant waste heat and the residual heat from the HT loop using R134a as the working fluid. The results show that the net power of the LT loop is higher than that of the HT loop (9.57 kW for the HT loop and $26.39 \mathrm{~kW}$ for the LT loop at the rated power point.).

3. The performance map of the combined system was evaluated using the first law method. In the peak effective thermal efficiency region, the augmentation proportion of the net power for the combined system was lowest at $14-16 \%$, but highest in the small load region where the augmentation proportion was 30-50\%. The effective thermal efficiency also significantly increases throughout the engine's operating region.

4. Analysis of the exergy destruction rate of the combined system shows that the performance can be further increased if the thermal efficiencies of the dual loops are improved or if the waste heat quantity in the condenser is reduced.

\section{Acknowledgments}

This work was sponsored by the National Basic Research (973) Program of China (Grant \# 2011CB707202, Grant \# 2011CB710704), the National High-Tech Research and Development Program of China (863 Program) (Grant No. 2009AA05Z206), and the Funding Project for Academic Human Resources Development in Institutions of Higher Learning Under the Jurisdiction of Beijing Municipality (Grant No. PHR201008019).

$\begin{array}{ll}\text { Nomenclature } \\ \dot{W} & \text { power }(\mathrm{kW}) \\ \dot{m} & \text { mass flow rate }(\mathrm{kg} / \mathrm{s}) \\ h & \text { enthalpy }(\mathrm{kJ} / \mathrm{kg}) \\ S & \text { entropy }(\mathrm{kJ} / \mathrm{kg} \mathrm{K}) \\ \dot{I} & \text { exergy destruction rate }(\mathrm{kW}) \\ T & \text { temperature }(\mathrm{K}) \\ P & \text { pressure }(\mathrm{MPa}) \\ \dot{Q} & \text { heat quantity }(\mathrm{kW}) \\ E & \text { exergy }(\mathrm{kJ}) \\ x & \text { mass fraction }\end{array}$

\section{Greek letters \\ $\eta \quad$ efficiency}

\section{Subscript \\ cr critical point \\ bp normal boiling point \\ $0 \quad$ reference state}

HT1, HT2, HT2s, HT3, HT4, HT4s state points in HT loop

LT1, LT2, LT2s, LT3, LT4, LTb, LT5, LT5s state points in LT loop

p1 pump 1

p2 pump 2

exh exhaust gas

in at the inlet

out at the outlet

$\begin{array}{ll}\text { e1 } & \text { evaporator 1 } \\ \text { e2 } & \text { evaporator } 2 \\ \text { s1 } & \text { expander 1 } \\ \text { s2 } & \text { expander 2 } \\ \text { pre } & \text { preheater } \\ \text { cool } & \text { coolant } \\ \text { c } & \text { condenser } \\ \text { mc } & \text { mean condensing temperature } \\ \text { f } & \text { fuel } \\ \text { a } & \text { intake air } \\ \text { b } & \text { brake } \\ \text { misc } & \text { miscellaneous } \\ \text { n } & \text { net } \\ \text { g } & \text { gasoline } \\ \text { eff } & \text { effective } \\ \text { cs } & \text { combined system } \\ \text { comb } & \text { combustion } \\ \text { HT } & \text { HT loop } \\ \text { LT } & \text { LT loop }\end{array}$

\begin{tabular}{ll}
\multicolumn{2}{l}{ Acronyms } \\
ORC & organic Rankine cycle \\
EGR & exhaust gas recirculation \\
HT & high temperature \\
LT & low temperature \\
AFR & air fuel ratio \\
b.s.f.c. & brake specific fuel consumption
\end{tabular}

\section{References}

[1] Desai NB, Bandyopadhyay S. Process integration of organic Rankine cycle. Energy 2009;34:1674-86.

[2] Sauret E, Rowlands AS. Candidate radial-inflow turbines and high-density working fluids for geothermal power systems. Energy 2011;36:4460-7.

[3] Hung TC, Wang SK, Kuo CH, Pei BS, Tsai KF. A study of organic working fluids on system efficiency of an ORC using low-grade energy sources. Energy 2010; 35:1403-11.

[4] Saleh B, Koglbauer G, Wendland M, Fischer J. Working fluids for lowtemperature organic Rankine cycles. Energy 2007;32:1210-21.

[5] Lai NA, Wendland M, Fischer J. Working fluids for high-temperature organic Rankine cycles. Energy 2011;36:199-211.

[6] Roy JP, Mishra MK, Misra A. Parametric optimization and performance analysis of a waste heat recovery system using organic Rankine cycle. Energy 2010;35:5049-62.

[7] Schuster A, Karellas S, Aumann R. Efficiency optimization potential in supercritical organic Rankine cycles. Energy 2010;35:1033-9.

[8] Teng H, Regner G, Cowland C. Achieving high engine efficiency for heavy-duty diesel engines by waste heat recovery using supercritical organic-fluid Rankine cycle. SAE 2006-01-3522, 2006.

[9] Little AB, Garimella S. Comparative assessment of alternative cycles for waste heat recovery and upgrade. Energy 2011;36:4492-504.

[10] Wang H, Peterson R, Harada K, Miller E, Ingram-Goble R, Fisher L, et al. Performance of a combined organic Rankine cycle and vapor compression cycle for heat activated cooling. Energy 2011;36:447-58.

[11] Wang H, Peterson R, Herron T. Design study of configurations on system COP for a combined ORC (organic Rankine cycle) and VCC (vapor compression cycle). Energy 2011;36:4809-20.

[12] Guo T, Wang HX, Zhang SJ. Selection of working fluids for a novel lowtemperature geothermally-powered ORC based cogeneration system. Energy Convers Manag 2011;52:2384-91.

[13] Guo T, Wang HX, Zhang SJ. Fluids and parameters optimization for a novel cogeneration system driven by low-temperature geothermal sources. Energy 2011;36:2639-49.

[14] Yamada N, Minami T, Mohamad MNA. Fundamental experiment of pumpless Rankine-type cycle for low-temperature heat recovery. Energy 2011;36: 1010-7.

[15] Vaja I, Gambarotta A. Internal combustion engine (ICE) bottoming with organic Rankine cycles (ORCs). Energy 2010;35:1084-93.

[16] Srinivasan KK, Mago PJ, Krishnan SR. Analysis of exhaust waste heat recovery from a dual fuel low temperature combustion engine using an organic Rankine cycle. Energy 2010;35:2387-99.

[17] Arias DA, Shedd TA, Jester RK. Theoretical analysis of waste heat recovery from an internal combustion engine in a hybrid vehicle. SAE 2006-01-1605, 2006. 
[18] Freymann R, Strobl W, Obieglo A. The turbosteamer: a system introducing the principle of cogeneration in automotive applications. MTZ 2008;69:404-12.

[19] Ringler J, Seifert M, Guyotot V, Hubner W. Rankine cycle for waste heat recovery of IC engines. SAE 2009-01-0174, 2009.

20] Aly SE. Diesel engine waste-heat power cycle. Appl Energy 1988;29:179-89.

[21] Pei G, Li J, Li Y, Wang D, Ji J. Construction and dynamic test of a small-scale organic Rankine cycle. Energy 2011;36:3215-23.

[22] Honyewell. Genertron ${ }^{\circledR} 245 \mathrm{fa}$ applications development guide. Morristown USA: Honeywell Fluorine Products; 2000.

[23] Wang EH, Zhang HG, Fan BY, Ouyang MG, Zhao Y, Mu QH. Study of working fluid selection of organic Rankine cycle (ORC) for engine waste heat recovery. Energy 2011;36:3406-18.

[24] Chen H, Goswami DY, Rahman MM, Stefanakos EK. A supercritical Rankine cycle using zeotropic mixture working fluids for the conversion of low-grade heat into power. Energy 2011;36:549-55.

[25] Wang JL, Zhao L, Wang XD. A comparative study of pure and zeotropic mixtures in low-temperature solar Rankine cycle. Appl Energy 2010;87: 3366-73.

[26] Tchanche BF, Papadakis G, Lambrinos G, Frangoudakis A. Fluid selection for a low-temperature solar organic Rankine cycle. Appl Thermal Eng 2009;29: 2468-76.
[27] Dai Y, Wang J, Gao L. Parametric optimization and comparative study of organic Rankine cycle (ORC) for low grade waste heat recovery. Energy Convers Manag 2009;50:576-82.

[28] Wang EH, Zhang HG, Fan BY, Liang H, Ouyang MG. Study of gasoline engine waste heat recovery by organic Rankine cycle. In: Proceedings of 2010 international conference on electrical engineering and automatic control; 2010 Nov 26-28, vol. 12. Zibo, China: IEEE; 2010. p. 44-8.

[29] National standard of the People's Republic of China. GB/T 18297-2001. 2001.

[30] Heywood JB. Internal combustion engine fundamentals. New York: McGrawHill; 1998.

[31] Zhou LB. Theory of internal combustion engine. Beijing: China Machine Press; 1999 [in Chinese].

[32] Poling BE, Prausnitz JM, O'Connell JP. The properties of gases and liquids. 5th ed. New York: McGraw-Hill; 2001.

[33] MATLAB version R14SP3, Matlab help. US: The MathWorks, Inc.; 2005.

[34] REFPROP version 8.0, NIST standard reference database 23. America: The U.S. Secretary of Commerce; 2007.

[35] Cengel YA, Boles MA. Thermodynamics - an engineering approach. 6th ed. London: McGraw-Hill; 2008

[36] Wark K, Richards DE. Thermodynamics. 6th ed. Singapore: McGraw-Hill; 1999. 